\title{
Internacionalização comercial e produtiva na indústria de cosméticos: desafios competitivos para empresas brasileiras
}

\author{
Renato Garcia \\ Departamento de Engenharia de Produção da Escola Politécnica da USP (EPUSP)
}

\begin{abstract}
Resumo
As formas de internacionalização produtiva têm ganhado importância crescente nas estratégias das grandes empresas de diversos setores. Na indústria de cosméticos, convergente com essa tendência geral, as grandes empresas têm procurado internacionalizar suas funções corporativas, em uma estratégia de busca de oportunidades de mercado em todo o mundo. Nesse contexto, este trabalho discute as formas de internacionalização das empresas de cosméticos, com o propósito de estabelecer um padrão de ação dessas organizações. Para isso, são investigados os dados do comércio internacional de produtos cosméticos e as estratégias de algumas das grandes empresas que atuam no mercado global. A partir das experiências das empresas internacionais, será possível extrair algumas implicações gerenciais que podem ser úteis para que as empresas brasileiras aumentem sua pequena participação no mercado internacional.
\end{abstract}

Palavras-chave

Indústria de cosméticos; internacionalização; competitividade.

\section{Comercialization and productive internacionalization in the cosmetic industry: competitive challenges for brazilian firms}

\begin{abstract}
The great companies on several industries are increasing their action in the international markets, not just even by selling globally their products, but also by foreign direct investments. In the cosmetic industry, in convergence with this general tendency, the big firms are increasing their international acting, in a strategy of looking for new market opportunities all around the world. In this way, this paper discusses the internationalization strategies of the cosmetic firms, with the objective to establish a standard of actions of the big firms. To do that, it is showed some data of the international trade of cosmetic products and the strategies of some of the big international firms that act in the global markets. By doing that, it will be possible to get some managerial implications to the Brazilian firms, in order to increase their small share in the international markets.
\end{abstract}

Key words

Cosmetics industry; internationalization; competitive advantages. 


\section{INTRODUC̣ÃO *}

Uma das características do processo recente de desenvolvimento empresarial é a tendência crescente de intensificação das estratégias de internacionalização das empresas. Convergente com esta tendência, tem-se verificado na indústria de cosméticos, empresas que têm procurado internacionalizar suas funções corporativas, em uma busca incessante de rentabilizar globalmente seus ativos produtivos, comerciais e tecnológicos.

Porém, é possível verificar a existência de um padrão de internacionalização das empresas, muitas vezes com evidentes especificidades setoriais. No caso da indústria de cosméticos, o estudo das estratégias de internacionalização das grandes empresas globais mostrou que há uma clara precedência de internacionalização da função comercial sobre as áreas produtiva e, sobretudo, tecnológica, que permanece fortemente concentrada nos países de origem. Além disso, outro condicionante dessas estratégias é a forma de atuação da empresa no mercado e sua linha de produtos.

Nesse contexto, este trabalho apresenta alguns elementos que permitem verificar essa tendência, a partir de dados internacionais de comércio e das estratégias das principais empresas globais. Para isso, são discutidas inicialmente as características do processo de internacionalização das empresas. Em seguida, é apresentado um breve panorama da indústria mundial, seu padrão de comércio e, especialmente, o que se refere à participação dos diferentes países no mercado mundial de cosméticos. Depois disso, são analisadas as estratégias das grandes empresas internacionais e, por fim, são apresentadas algumas implicações para as empresas brasileiras. A fonte das informações apresentadas foi o levantamento de informações corporativas brasileiras e internacionais e junto a fontes secundárias, basicamente revistas especializadas, além de visitas e entrevistas realizadas nas principais empresas que atuam no setor.

Desde logo, é preciso ressaltar que a heterogeneidade produtiva é uma característica marcante dessa indústria. A presença de grandes empresas internacionais, diversificadas ou especializadas nos segmentos de perfumaria e cosméticos, é contrastada com um grande número de pequenas e médias empresas com atuação focalizada na produção de cosméticos. A vasta quantidade de pequenas e médias empresas decorre, principalmente, da simplicidade da base técnica de importantes segmentos do setor, que se caracterizam pela manipulação de fórmulas relativamente simples. Nesse sentido, é comum encontrar casos de empresas de cosméticos que se desenvolveram a partir de um negócio de farmácia de manipulação ${ }^{1}$.

\section{O PROCESSO DE INTERNACIONALIZACÃO DAS EMPRESAS NO PERÍODO RECENTE}

O processo recente de internacionalização das grandes empresas provocou o incremento da importância das grandes empresas internacionais (ou multinacionais como são mais conhecidas), que se consolidaram como o principal locus de acumulação e de poder econômico. Essa posição foi solidificada a partir do domínio de um conjunto de ativos específicos e crescentemente intangíveis, como capital, tecnologia e capacidades gerencial, organizacional e mercadológica. As grandes empresas internacionais nesse sentido configuram-se no principal agente do processo de internacionalização da produção e das demais operações, que se expressa de três formas mais importantes: exportação de bens, licenciamento de ativos e investimento direto externo (GONÇALVES, 2002).

\section{A s grandes empresas internacionais configuram-se no principal agente processo de internacionalização da produção e das demais operações}

A expansão dos fluxos de investimento direto externo (IDE) no período recente tem reforçado a importância dessas empresas, mesmo que esses investimentos estivessem menos associados à criação de novas capacidades manufatureiras, mas sim com vultosos processos de fusões e aquisições. Chesnais (1996) observou que a expansão das empresas transnacionais insere-se em um amplo processo de mundialização do capital, em que o processo de acumulação e concorrência capitalista passou a se dar crescentemente no âmbito global e com a formação de diversos oligopólios mundiais, em substituição dos antigos oligopólios nacionais.

Existem diversas interpretações para o fenômeno da expansão do $\mathrm{IDE}^{2}$. Uma das razões que justificam a expansão internacional das empresas são os fatores específicos à propriedade, já que permitem às empresas explorar vantagens competitivas relativas à propriedade de determinados ativos diferenciados, como segredo industrial, patentes e marcas próprias. Essa forma de expansão também pode ocorrer por meio do licenciamento desses ativos diferenciados, mas que embute riscos mais elevados. 
Para Dunning (1993), que apresentou o chamado paradigma eclético, em uma tentativa de integrar diversas das abordagens sobre a expansão das grandes empresas internacionalizadas, os fatores que estimulam a expansão do IDE estão fortemente relacionados às restrições dos movimentos dos fatores. Assim, as empresas tendem a realizar investimentos externos quando encontram nos países hospedeiros vantagens associadas tanto com a existência de fontes de matéria-prima (resource seeking), como os reduzidos custos de mão-de-obra (efficiency seeking). Além disso, elevados custos de transporte também justificam a expansão do IDE. que normalmente tem o papel de coordenar atividades de comercialização e logística de distribuição, mesmo quando essa tarefa é realizada por terceiros. Já o quarto estágio envolve a instalação de unidades de produção no exterior, aliada ou não ao estabelecimento de um centro de desenvolvimento de produtos. Muitas vezes, essa estratégia é decorrente de arranjos organizacionais como licenciamento ou joint-ventures.

No caso da indústria brasileira de cosméticos, grande parte dos investimentos das grandes empresas internacionais no Brasil esteve relacionado com a oportunidade de atendimento do mercado doméstico e, em menor medida e mais recentemente, regional. As empresas estabeleceram grandes unidades de manufatura no Brasil, especialmente em produtos que possuem escalas mais elevadas de produção, como forma de atender o mercado local. Nesse sentido, o estabelecimento dessas plantas produtoras, assim como de complexos sistemas de comercialização e de logística de distribuição, exerce papel fundamental para que essas empresas obtenham vantagens competitivas no mercado local, tarefa que dificil-

A capacitação tecnológica, mesmo que vista como uma variável de estoque, também pode ser um motivo para a expansão internacional das grandes empresas, que buscam apropriar-se por meio do IDE de ativos específicos como o conhecimento tecnológico e a capacidade mercadológica (GONÇALVES, 2002). Nesse contexto, e associadas com as políticas comerciais dos diferentes países, podem ser verificadas estratégias do tipo market seeking, como forma utilizada pelas grandes empresas internacionalizadas para ter acesso ao mercado dos países hospedeiros. Como observou Gonçalves (2002), no caso dos países em desenvolvimento, as medidas de políticas voltadas à substituição de importações, que envolveram normalmente restrições ao livre comércio, estimularam o ingresso de grandes empresas internacionais, já que essas empresas foram impedidas de exportar seus produtos para os mercados locais.

Já do ponto de vista da firma, Andersen (1993) aponta que existem alguns estágios no processo de internacionalização das empresas. O primeiro estágio é a expansão dos mercados da firma por meio de exportações de caráter eventual e não regular, que se configura como uma forma absolutamente incipiente de internacionalização. Em seguida, o segundo estágio se caracteriza pela expansão mais vultosa das exportações, por meio principalmente da contratação de representantes nos mercadosdestino em que a empresa pretende atuar. O terceiro estágio é o estabelecimento de uma subsidiária no exterior, mente seria cumprida com a mesma eficiência se as empresas não internalizassem parte importante de suas operações. Isso ocorre mesmo quando as empresas simplesmente adaptam seus produtos globais ao mercado doméstico, caso bastante comum na indústria brasileira de cosméticos.

\section{O PANORAMA MUNDIAL DA INDÚSTRIA DE COSMÉTICOS}

Uma dificuldade inicialmente encontrada na análise da indústria de cosméticos é a sua definição e delimitação. Normalmente, o setor de cosméticos é definido segundo o objetivo da utilização de seus principais produtos. Assim, estariam entre os cosméticos produtos destinados à aplicação no corpo humano para limpeza, embelezamento, ou para alterar sua aparência sem afetar sua estrutura ou funções.

Nesse sentido, a noção de cosméticos vincula-se com produtos destinados essencialmente à melhoria da aparência do consumidor. Normalmente, o setor é subdividido em três segmentos: (i) perfumaria: pós-barba, deocolônias e essências; (ii) cosméticos: cremes em geral, maquiagens, produtos para unhas e tintura; e (iii) higiene pessoal: pasta de dente, papel higiênico, xampu, sabonete, fralda descartável, bloqueador solar. Contudo, é plausível afirmar que as linhas de separação entre tais subdivisões são bastante tênues, uma vez que o setor/segmento de cosméticos tem proximidade tanto com os outros 
segmentos, quanto com outros setores, como farmacêutico e químico. Essa afirmação encontra respaldo tanto na forma de regulação do setor, quanto na estratégia das maiores empresas ou ainda nos encadeamentos com outros setores da cadeia de suprimentos.

De uma forma geral, juntos, os segmentos de perfumaria, higiene pessoal e limpeza respondem por algo em torno de $1 / 8$ da produção da indústria química mundial, como mostra a Tabela $1^{3}$.

Como se vê pela tabela, o peso da produção de cosméticos e dos outros segmentos afins na indústria química apresenta algumas variações de acordo com a região analisada. No caso da Europa Ocidental o peso desse segmento alcança $14 \%$ e no Japão $12 \%$, regiões com níveis médios de renda pessoal mais elevados e com hábitos de consumo bastante sofisticados no que se refere ao trato da aparência ${ }^{4}$. Já no caso da China, o peso desse segmento é relativamente mais reduzido, em torno de $8 \%$ da produção total da indústria química. Além de um padrão de consumo diferenciado, os dados mostram também a distinta especialização produtiva dos países.

Já em termos da evolução do faturamento mundial da indústria de cosméticos, mostrada na Tabela 2, vê-se que, em 1998, atingiu o valor de US\$ 167 bilhões, o que representou um crescimento total de 14\% sobre o valor de 1990 .

Analisando os valores por região, observa-se que na Europa Ocidental o valor do faturamento total do setor em 1998 foi de US\$ 64 bilhões, com um crescimento de $15 \%$ em relação a 1990. Na região do Nafta o crescimento foi de $30 \%$, atingindo US\$ 42 bilhões em 1998, enquanto no Japão o faturamento total foi de US\$ 21 bilhões. Essas três regiões somadas foram responsáveis por $75 \%$ do volume de vendas do setor em 1998, com o restante do montante distribuído pelas outras regiões menos desenvolvidas.

Em termos dos principais mercados mundiais de produtos de higiene pessoal, perfumaria e cosméticos, percebe-se que os Estados Unidos respondem por uma elevada parcela do consumo mundial de produtos da indústria de cosméticos, como mostra a Tabela 3.

Vale notar o elevado peso do consumo de produtos cosméticos nos países desenvolvidos, já que os cinco principais mercados mundiais, respectivamente Estados Unidos, Japão, Alemanha, França e Inglaterra, respondem por pouco mais da metade do consumo mundial desses produtos.

O mercado brasileiro é bastante expressivo, já que é estimado como sendo da ordem de US $\$ 8,5$ bilhões, o que representa pouco mais de $4 \%$ do mercado mundial, uma participação muito superior à que caracteriza os mercados de tantos outros produtos (entre 1 e $2 \%$ ). Essa importância é atestada pela presença das grandes empresas internacionais do setor, que possuem atividades produtivas e comerciais bastante relevantes no Brasil.

Tabela 1: Participação da indústria de cosméticos, higiene e limpeza na produção da indústria química mundial por região - 1996.

\begin{tabular}{|c|c|c|c|c|c|c|c|c|}
\hline REGIÃO & $\begin{array}{c}\text { QUÍMIGA } \\
\text { DE } \\
\text { BASE }\end{array}$ & $\begin{array}{c}\text { PLÁSTICOS, } \\
\text { BORRACHA } \\
\text { E FIBRAS }\end{array}$ & $\begin{array}{c}\text { FERTILIZANTES } \\
\text { E } \\
\text { DEFENSIVOS }\end{array}$ & $\begin{array}{l}\text { TINTAS E } \\
\text { VERNIZES }\end{array}$ & $\begin{array}{l}\text { FARMA- } \\
\text { CÊUTICA }\end{array}$ & $\begin{array}{c}\text { COSMÉTICOS } \\
\text { HIGIENE E } \\
\text { LIMPEZA }\end{array}$ & OUTROS & TOTAL \\
\hline Europa Ocidental & 25 & 17 & 5 & 7 & 24 & 14 & 9 & 100 \\
\hline América do Norte & 28 & 17 & 6 & 5 & 23 & 10 & 12 & 100 \\
\hline Extremo Oriente & 28 & 20 & 7 & 5 & 20 & 10 & 9 & 100 \\
\hline - Japão & 23 & 21 & 3 & 6 & 25 & 12 & 11 & 100 \\
\hline - China & 39 & 10 & 17 & 2 & 18 & 8 & 6 & 100 \\
\hline - Outros Países & 29 & 27 & 7 & 6 & 12 & 10 & 9 & 100 \\
\hline
\end{tabular}

Fonte: Chemical Industry Association; extraído de Garcia et al. (2000).

Tabela 2: Faturamento do setor de cosméticos no mundo e por região — US\$ milhões — 1990 e 1998.

\begin{tabular}{|l|c|c|c|}
\hline \multicolumn{1}{|c|}{ REGIÃO } & $\mathbf{1 9 9 0}$ & $\mathbf{1 9 9 8}$ & CRESCIMENTO TOTAL (\%) \\
\hline Mundo & 147.000 & 167.160 & 14 \\
\hline Europa Ocidental & 55.739 & 64.369 & 15 \\
\hline NAFTA & 32.637 & 42.407 & 30 \\
\hline Japão & 19.539 & 21.312 & 9 \\
\hline
\end{tabular}

Fonte: Estimativa a partir de FEDERCHIMICA, CEFIC e ABIQUIM; extraído de Garcia et al. (2000). 
Já no que se refere ao comércio internacional, percebe-se que os produtos de perfumaria, cosméticos e higiene pessoal possuem participação significativa na pauta de exportações de diversos países. A Tabela 4 mostra os principais países exportadores mundiais e o volume de comércio relativo a cada um deles.

Como se vê, os principais exportadores são países desenvolvidos, com imenso destaque para a França, cujas vendas externas ultrapassam o patamar dos US\$ 5,7 bilhões anuais. Em seguida, Estados Unidos, com cerca de US\$ 2,8 bilhões, Reino Unido (US\$ 2,4 bilhões), Alemanha (US \$ 2,3 bilhões) e Itália (US\$ 1,2 bilhão). O Brasil ocupa a modesta 28 a posição, com um total de exportações que alcançou em 2000 US\$ 73 milhões, a despeito de que esse volume se elevou significativamente ao longo da segunda metade da década de 90 .
Já a Tabela 5 mostra os principais importadores. Mais uma vez, percebe-se a importância dos países desenvolvidos, que ocupam as primeiras posições no ranking dos maiores importadores.

Os dados de importações mostram que os principais países compradores internacionais de produtos cosméticos (bens finais) são, da mesma forma, países desenvolvidos. O maior importador em 2000 eram os Estados Unidos, que apresentaram compras externas totais de US\$ 2,4 bilhões, seguidos pela Alemanha (US\$1,7 bilhão), Inglaterra (US\$ 1,6 bilhão), França (US\$ 1,1 bilhão) e Japão (US\$ 1,1 bilhão). O Brasil também aparece em posição pouco expressiva, com um total importado de US\$ 146 milhões (o que revela o saldo comercial negativo desses produtos).

Porém, é interessante notar que, a despeito de serem grandes importadores, o saldo comercial desses países é,

Tabela 3: Principais mercados nacionais de produtos de higiene pessoal, perfumaria e cosméticos — US\$ bilhões -2000 .

\begin{tabular}{|c|c|c|}
\hline País & MERCADO & PARTICIPAÇÃO \% \\
\hline 1. Estados Unidos & 47,6 & 24,4 \\
\hline 2. Japão & 23,0 & 11,8 \\
\hline 3. Alemanha & 9,8 & 5,0 \\
\hline 4. França & 9,3 & 4,8 \\
\hline 5. Reino Unido & 9,0 & 4,6 \\
\hline 6. Brasil & 8,5 & 4,4 \\
\hline 7. Itália & 7,1 & 3,7 \\
\hline 8. China & 5,6 & 2,9 \\
\hline 9. México & 4,4 & 2,2 \\
\hline 10. Espanha & 4,3 & 2,2 \\
\hline TOP 10 & 128,6 & 66,0 \\
\hline TOTAL & 195,0 & 100,0 \\
\hline
\end{tabular}

Fonte: Euromonitor; extraído de ABIHPEC

Tabela 4: Principais exportadores mundiais de produtos de perfumaria, cosméticos e higiene pessoal - bens finais - US\$ milhões.

\begin{tabular}{|l|r|r|r|r|r|}
\hline \multicolumn{1}{|c|}{ PAís } & 1996 & 1997 & 1998 & 1999 & 2000 \\
\hline 1. França & 5.877 & 5.763 & 5.848 & 5.898 & 5.750 \\
\hline 2. Estados Unidos & 2.178 & 2.602 & 2.561 & 2.572 & 2.844 \\
\hline 3. Reino Unido & 2.270 & 2.612 & 2.500 & 2.439 & 2.376 \\
\hline 4. Alemanha & 2.043 & 2.124 & 2.370 & 2.274 & 2.335 \\
\hline 5. Itália & 1.006 & 1.002 & 1.172 & 1.190 & 1.264 \\
\hline 6. Espanha & 446 & 530 & 648 & 734 & 758 \\
\hline 7. Bélgica* & 680 & 658 & 693 & 744 & 740 \\
\hline 8. Canadá & 360 & 411 & 431 & 460 & 552 \\
\hline 9. Japão & 347 & 399 & 397 & 473 & 545 \\
\hline 10. Irlanda & 517 & 538 & 521 & 59 & 505 \\
\hline 28. Brasil & 52 & 55 & 58 & 73 \\
\hline
\end{tabular}

Fonte: Comtrade, SITC 553 "Perfume/ toilet/ cosmetics"; dados ordenados pelas exportações de 2000. Obs.: * até 1998 inclui Luxemburgo. 
em geral, positivo, dada a posição de, ao mesmo tempo, grandes exportadores de produtos cosméticos. Esse fenômeno pode ser visto na Tabela 6 .

Como mostra a tabela, deve-se destacar a posição da França que, a despeito do elevado volume de compras externas, apresentou em 2000 um saldo positivo bastante expressivo, da ordem de US\$ 4,6 bilhões. Em seguida, é possível identificar nos próximos quatro países (respectivamente, Estados Unidos, Inglaterra, Alemanha e Itália) um comportamento semelhante: são ao mesmo tempo grandes exportadores e importadores, mas apresentam saldos comerciais positivos e relativamente expressivos.

Essa constatação é de suma importância para a compreensão não apenas da dinâmica do padrão de comércio internacional, mas também do sistema de regulação que a ele está vinculado. Por serem os grandes atores do comércio mundial, os países desenvolvidos praticam níveis de proteção tarifária bastante reduzidos e praticamente não utilizam outras formas de salvaguardas nãotarifárias. Em virtude dessa prática, fica evidente que o acesso aos grandes mercados consumidores de produtos cosméticos não é restringido por barreiras comerciais às importações desses países, já que não existem tarifas relevantes ou sequer outros tipos de restrição comercial, como padrões ou regulamentações.

Nesse sentido, a baixa participação dos países em desenvolvimento nos grandes mercados consumidores mundiais deve-se à existência de fortes barreiras econômicas ao processo competitivo nesses mercados. Isso decorre sobretudo da elevada capacidade técnica e produtiva das empresas dos países centrais, o que impede o crescimento de empresas de países em desenvolvimento nesses mercados. Significa dizer que as tradicionais vantagens competitivas estáticas que sustentam a participa-

Tabela 5: Principais importadores mundiais de produtos de perfumaria, cosméticos e higiene pessoal - bens finais - US\$ milhões.

\begin{tabular}{|rl|r|r|r|r|r|}
\hline \multicolumn{1}{|c|}{ PAís } & $\mathbf{1 9 9 6}$ & $\mathbf{1 9 9 7}$ & $\mathbf{1 9 9 8}$ & $\mathbf{1 9 9 9}$ & $\mathbf{2 0 0 0}$ \\
\hline 1 & Estados Unidos & 1.500 & 1.640 & 1.825 & 2.061 & 2.375 \\
\hline 2 & Alemanha & 1.713 & 1.573 & 1.856 & 1.815 & 1.703 \\
\hline 3 & Reino Unido & 1.208 & 1.304 & 1.448 & 1.507 & 1.642 \\
\hline 4 & França & 989 & 1.049 & 1.147 & 1.167 & 1.123 \\
\hline 5 & Japão & 866 & 939 & 852 & 1.002 & 1.103 \\
\hline 6 & Itália & 901 & 896 & 1.002 & 1.068 & 1.040 \\
\hline 7 & Canadá & 692 & 758 & 821 & 879 & 948 \\
\hline 8 & Espanha & 626 & 647 & 730 & 785 & 773 \\
\hline 9 & Holanda & 655 & 575 & 578 & 688 & 665 \\
\hline 10 & Hong Kong & 712 & 722 & 616 & 597 & 661 \\
\hline 30 & Brasil & 91 & 152 & 158 & 128 & 146 \\
\hline
\end{tabular}

Fonte: Comtrade, SITC 553 "Perfume/ toilet/ cosmetics"; dados ordenados pelas importações de 2000.

Tabela 6: Principais países participantes do comércio mundial de produtos de perfumaria, cosméticos e higiene pessoal - bens finais - exportações, importações e saldo comercial - em US\$ milhões - 2000.

\begin{tabular}{|l|c|c|c|}
\hline \multicolumn{1}{|c|}{ PAís } & EXPORTAÇÕES & IMPORTAÇÕES & SALDO COMERCIAL \\
\hline França & 5.750 & 1.123 & 4.627 \\
\hline Estados Unidos & 2.844 & 2.375 & 469 \\
\hline Reino Unido & 2.376 & 1.642 & 734 \\
\hline Alemanha & 2.335 & 1.703 & 632 \\
\hline Itália & 1.264 & 1.040 & 224 \\
\hline Espanha & 758 & 773 & $(15)$ \\
\hline Bélgica & 740 & 616 & 124 \\
\hline Canadá & 552 & 948 & $(396)$ \\
\hline Japão & 545 & 1.103 & 185 \\
\hline Irlanda & 505 & 321 & $(73)$ \\
\hline Brasil & 73 & 146 & \\
\hline
\end{tabular}

Fonte: Comtrade, SITC 553 "Perfume/ toilet/ cosmetics". 
ção dos países em desenvolvimento no mercado mundial, relacionadas com os baixos salários, a ausência de regulamentação mais eficaz e com o acesso a fontes privilegiadas de matéria-prima, são muito pouco importantes para o processo de competição na indústria de cosméticos.

$\mathrm{Na}$ verdade, são as capacidades técnico-produtivas e tecnológicas os reais determinantes da participação dos atores no mercado internacional. A isso se associa a presença das grandes empresas internacionais nos seus respectivos mercados de origem, onde geralmente essas empresas mantêm suas unidades produtoras mais importantes, especialmente de produtos mais sofisticados, e seus laboratórios de desenvolvimento de produto. diversas subsidiárias das grandes empresas internacionais, que também possuem atividades relevantes de fabricação de produtos cosméticos e higiene pessoal no país. Porém, o ingresso dessas empresas no Brasil esteve associado a uma estratégia de atendimento da demanda doméstica, e eventualmente regional, de modo que as empresas exportam parcelas pouco significativas da produção. Ao contrário, muitas empresas são, por meio do comércio intrafirma, importadoras de produtos mais sofisticados, cuja produção é centralizada, em geral, na matriz, em virtude das escalas de produção.

Portanto, o exame das características do padrão de comércio internacional na indústria de cosméticos revela elementos importantes das estratégias das empresas do setor, especialmente no que se refere às suas formas de internacionalização. Como se pode perceber, um pré-requisito ao estabelecimento no exterior de unidades produtoras é a internacionalização dos ativos comerciais, já que as empresas procuram inicialmente estabelecer suas marcas e canais de comercialização nos mercados externos. Somente depois disso,

Isso é absolutamente convergente com a baixa participação do Brasil no mercado mundial. Pelas tabelas apresentadas acima, vê-se que o país tem importância reduzida nos fluxos de comércio internacional da indústria, já que ocupa a $28^{\mathrm{a}}$ posição entre os maiores exportadores e a $30^{\underline{a}}$ entre os importadores. A posição do Brasil no mercado mundial é um retrato bastante fiel do padrão de inserção dos países em desenvolvimento no mercado internacional da indústria de cosméticos. Vale destacar que as importações brasileiras superam em duas vezes as exportações, o que se traduz em um saldo negativo da ordem de pouco mais de US\$ 70 milhões (Tabela 6). Esse saldo vem se reduzindo nos últimos anos, mas ainda permanece em patamares negativos importantes.

Essa baixa participação do Brasil no mercado internacional revela ao menos duas características muito importantes do padrão de concorrência do setor e das estratégias das empresas que atuam no mercado brasileiro, que como foi visto anteriormente (Tabela 3) representa o $6^{-}$ maior mercado do mundo. Primeiro, nota-se a dificuldade das empresas brasileiras em participar mais ativamente do comércio mundial desses produtos, já que elas se deparam com os grandes atores internacionais que já atuam nos principais mercados mundiais. Daí decorre a baixa participação dessas empresas nesses mercados, dadas as dificuldades de construção de ativos comerciais nesses países, especialmente de marcas próprias e canais de comercialização e distribuição dos produtos.

Segundo, é possível notar no Brasil a presença de e apenas em países cujos mercados domésticos são expressivos, é que as empresas vão estabelecer unidades de fabricação de produtos cosméticos.

Outro elemento que revela o padrão competitivo do setor na economia brasileira, e mostra alguns elementos da estratégia das grandes empresas internacionais no Brasil, pode ser verificado na análise do destino das exportações e da origem das importações da balança comercial da indústria brasileira de cosméticos (Tabela 7).

Como mostra a tabela, o principal destino das vendas externas brasileiras é a Argentina, que respondeu em 2001 por quase $20 \%$ das exportações totais. À exceção dos Estados Unidos, que eram responsáveis pela compra de pouco mais de $13 \%$ das exportações brasileiras te como destino das vendas externas da indústria brasileira eram da América do Sul, como Paraguai (7,2\%), Chile (6,8\%), Bolívia, Colômbia e Uruguai (pouco mais de $3 \%$ cada). No ranking dos 10 maiores destinos das exportações apenas três países não se localizavam na América Latina.

Já a análise da origem das importações mostra um quadro absolutamente distinto. A principal origem das importações brasileiras eram, ao contrário do destino das exportações, os países desenvolvidos. Dos cinco principais vendedores de produtos cosméticos para o Brasil (que representa quase $3 / 4$ das importações totais), quatro são países desenvolvidos, como Estados Unidos (21,6\%), França (19,2\%), Alemanha (12,7\%) e Suíça totais, todos os países que tiveram participação relevan- 
(5\%). Apenas a Argentina aparece com algum destaque, já que era origem de $15,5 \%$ das importações.

Esse padrão de comércio da indústria brasileira de cosméticos, que é absolutamente convergente com o cenário mundial, revela uma face muito importante do processo de internacionalização que marca essa indústria. As grandes empresas internacionais abastecem os mercados-destino em que atuam por meio de unidades produtoras concentradas nos países desenvolvidos, notadamente nos seus respectivos países de origem. Isso corrobora a conclusão de que a desconcentração produtiva só ocorre quando se verificam escalas de produção mais expressivas dos mercados de destino, como é o caso das operações de diversas empresas internacionais no Brasil, que atuam especialmente no segmento de higiene pessoal. A partir dessa base produtiva inclusive a empresa abastece o mercado doméstico e o regional, como demonstram os dados de exportações para o Mercosul e outros países da América do Sul

Por outro lado, e reforçando esse fenômeno, as estratégias de expansão internacional da indústria brasileira, ainda tímidas em seu montante e em seus valores, estão fortemente direcionadas para os países vizinhos, notadamente Mercosul e outros países da América do Sul. Diversas empresas brasileiras têm concentrado seus esforços de internacionalização na expansão de suas operações nos mercados mais próximos, especialmente por meio da tentativa de estabelecimento de ativos comerciais, tanto suas marcas como canais de comercialização, nos países latino-americanos.

Tabela 7: Padrão de comércio da indústria brasileira de cosméticos: destino das exportações e origem das importações - em \% - 2001.

\begin{tabular}{|lr|lr|}
\hline \multicolumn{2}{|c|}{ EXPORTAÇÕES } & \multicolumn{2}{c|}{ IMPORTAÇÕES } \\
\hline Argentina & 19,3 & Estados Unidos & 21,6 \\
\hline Estados Unidos & 13,8 & França & 19,2 \\
\hline Paraguai & 7,2 & Argentina & 15,5 \\
\hline Chile & 6,8 & Alemanha & 12,7 \\
\hline Bolívia & 3,6 & Suíça & 5,0 \\
\hline Colômbia & 3,6 & Chile & 4,6 \\
\hline Uruguai & 3,2 & Uruguai & 4,6 \\
\hline Países Baixos & 2,9 & Países Baixos & 2,6 \\
\hline Alemanha & 2,7 & Itália & 2,6 \\
\hline México & 2,5 & Espanha & 2,5 \\
\hline Peru & 2,5 & México & 1,5 \\
\hline Venezuela & 2,4 & Reino Unido & 1,3 \\
\hline Total (US\$ milhões)133,4 & Total (US\$ milhões)222,9 \\
\hline
\end{tabular}

Fonte: Secex; capítulo 33 - "Óleos essenciais e resinóides; produtos de perfumaria ou de toucador preparados e preparações cosméticas" e 34.01 - "Sabões; produtos e preparações orgânicas tensoativas". Não inclui a rubrica "Dentifrícios".
Esforços de internacionalização das empresas de cosméticos em outros países e continentes são raros e incipientes, a despeito de importantes. Os casos mais relevantes são o das empresas Natura, que anunciou que pretende expandir-se no mercado europeu, a partir de investimentos em canais de comercialização na França (EXAME, 5/3/03), e O Boticário, que já abriu diversas lojas franqueadas no exterior, em países como Portugal e México (EXAME, 24/4/03). As estratégias de internacionalização das empresas brasileiras, independentemente do mercado-destino, somente poderão ser bemsucedidas se as firmas forem capazes de, em primeiro lugar, estabelecer ativos comerciais próprios nos mercados de destino, por meio da fixação de marcas e da construção de canais de comercialização e distribuição dos produtos nesses mercados.

Nesse sentido, parece importante compreender melhor a estratégia das grandes empresas internacionalizadas que atuam na indústria de cosméticos. Somente por meio do entendimento das estratégias das grandes empresas internacionais é que se torna possível empreender implicações, lições e desdobramentos para o processo de internacionalização das empresas brasileiras de cosméticos.

\section{PRINCIPAIS ATORES DA INDÚSTRIA DE COSMÉTICOS: AS ESTRATÉGIAS DAS GRANDES EMPRESAS INTERNACIONAIS}

A diversidade e a heterogeneidade que marcam a indústria de cosméticos, já apontada neste trabalho, pode ser claramente verificada pela existência de uma multiplicidade de estratégias e de experiências de empresas que atuam no mercado mundial do setor. Essas empresas, muitas delas de dimensões e estratégias globais, possuem em diversos casos ligações importantes com atividades farmacêuticas e de alimentos, aproveitando as economias de escala e de escopo decorrentes da proximidade entre elas.

Nesse sentido, podem ser identificadas duas formas básicas com que se organizam as grandes empresas internacionais do setor.

A primeira delas compreende as grandes empresas diversificadas, que atuam na indústria de cosméticos e se aproveitam das economias de escala e de escopo com atividades correlatas como higiene pessoal, perfumaria, farmacêutica e até alimentos. Entre tais empresas, destacam-se alguns exemplos:

(i) A anglo-holandesa Unilever, cujo faturamento em 2001 ultrapassou o patamar dos US $\$ 51$ bilhões, é talvez a mais diversificada das empresas que atuam no setor, já que atua nos segmentos de higiene pessoal (24\% da receita), aí incluídos os produtos cosméticos, alimentos (23\%), higie- 
ne e limpeza (20\%), óleos e margarinas (17\%), sorvetes e bebidas (15\%) e outros (1\%).

(ii) A estadunidense Procter \& Gamble, que apresentou faturamento de US\$ 39 bilhões em 2001, fortemente concentrada em produtos de higiene pessoal, mas $18 \%$ oriundos das atividades denominadas de "beauty care"; suas principais marcas na área de cosméticos são Max Factor, Olay e Covergirl.

(iii) A também estadunidense Johnson \& Johnson, que faturou em 2001 US\$ 33 bilhões; possui a unidade Neutrogena que agrega as atividades de cosméticos e higiene pessoal (personal care).

(iv) Outra estadunidense importante é a Colgate-Palmolive, que faturou quase US\$ 9,5 bilhões em 2001, em virtude basicamente de sua atuação nos segmentos de produtos para higiene bucal e higiene pessoal.

Nessas empresas, as estratégias voltadas ao setor de cosméticos confundem-se com as de outros segmentos, como fica claro pelos seus elevados graus de diversificação. Elas se aproveitam das economias de escala e de escopo que se verificam entre essas atividades, tanto no que se refere à produção, quanto à pesquisa e à comercialização. Por exemplo, a pesquisa e desenvolvimento de novos produtos, um importante fator de competitividade para a indústria, por vezes, pode estar associado a outras áreas (como a farmacêutica) e prover resultados importantes para produtos cosméticos.

$\mathrm{O}$ mesmo fenômeno se verifica no que se refere à distribuição e comercialização dos produtos, já que as empresas se utilizam dos mesmos canais para a venda de produtos cosméticos e de higiene pessoal. Como se trata, em geral, de produtos fabricados em larga escala, as empresas comercializam seus produtos fundamentalmente por meio dos canais de varejo tradicionais, com grande participação dos supermercados e hipermercados.

A segunda forma básica em que se configuram as estratégias das empresas do setor é, em contraste com as experiências apontadas, a de empresas com atuação concentrada na indústria de cosméticos e, por vezes, perfumaria. Dentre as empresas internacionais que atuam desta forma, encontram-se:

(i) $\mathrm{O}$ grupo francês L'Oreal, que alcançou um faturamento mundial em 2001 de US\$13,6 bilhões e é proprietário (ou licenciado) de diversas marcas internacionais, entre elas L'Oreal Paris, Biotherm, Giorgio Armani, Helena Rubinstein, Laboratories Garnier, Lancôme, Maybelline, Ralph Lauren, Cacharel, entre outras; como se vê, trata-se de marcas estabelecidas mundialmente.

(ii) $\mathrm{O}$ grupo japonês Shiseido, que teve receitas totais em 2001 da ordem de US $\$ 5$ bilhões a partir de operações concentradas em cosméticos, produtos para banho e ou- tros ligados ao setor (produtos para salões de beleza, alimentos para saúde e beleza, entre outros).

(iii) A estadunidense Estee Lauder, que faturou em 2001 US\$ 4,6 bilhões, possui entre suas principais marcas Estee Lauder, Clinique, Aramis, Origins, Bobbi Brown, Aveda, Bumble and Bumble, entre outras, alem de ser licenciada das fragrâncias Tommy Hilfiger, Dona Karan e Kate Spade.

(iv) A também estadunidense Revlon, que atua exclusivamente na indústria de cosméticos, faturou em 2001 US\$ 1,3 bilhão e possui marcas como Absolutely Famous, Charlie, Colorsilk, High Dimension, entre outras.

(v) A empresa Coty, subsidiária da holding holandesa Benckiser, faturou US\$ 1,6 bilhão em 2001 e possui as marcas Lancaster, Davidoff, Isabella Rossellini, Jeniffer Lopez, entre outras.

Essas empresas concentram suas atividades, produtivas e tecnológicas, na indústria de cosméticos. Trata-se geralmente de produtos mais sofisticados, em que as escalas de produção são menos importantes relativamente a outros atributos do produto relacionados à diferenciação. Nesse sentido, são muito importantes competências como a capacidade inovativa, a incorporação de essências e fragrâncias diferenciadas e a embalagem.

Além disso, essas empresas combinam arrojadas estratégias tecnológicas com uma atuação mundial. Um exemplo ilustrativo é o da empresa francesa L'Oreal, cujo faturamento é oriundo $49 \%$ da Europa Ocidental, $32 \%$ da América do Norte e os $20 \%$ restantes distribuídos pelas outras regiões do globo. Além disso, a empresa vem empreendendo uma política de aquisições com o intuito de consolidar sua posição nos diversos mercados nacionais. Somente no Mercosul, por exemplo, de acordo com informações corporativas, a empresa adquiriu em janeiro de 2000, na Argentina, a Miss Yang S.A. e em julho de 2001, no Brasil, a Colorama.

Outra distinção dessas empresas em relação ao caso anterior, que em parte decorre da natureza do produto, é a forma de comercialização. As empresas com atuação concentrada na indústria de perfumaria e cosméticos adotam estratégias de comercialização de seus produtos através de lojas especializadas em perfumaria e cosméticos, ao invés dos supermercados e hipermercados, intensamente utilizados pelas grandes empresas diversificadas.

Uma variação dessa estratégia concentrada é a estratégia das empresas que comercializam seus produtos por meio das vendas diretas (door-to-door). Os casos mais importantes dessa variante são:

(i) A estadunidense Avon, que obteve um faturamento em 2001 de US\$ 5,9 bilhões. 
(ii) A Mary Kay, também dos Estados Unidos, que teve receitas totais de US\$ 1,3 bilhão em 2001.

(iii) A Nu Skin, outra empresa estadunidense, que faturou US\$ 880 milhões em 2001.

A importância desse segmento de produtos cosméticos pode ser mensurada pela elevada participação das vendas diretas no total da receita da indústria cosmética nos Estados Unidos, da ordem de $10 \%$, e que movimentou em 1999 US\$ 23 bilhões ${ }^{5}$. Uma característica dessas operações, nos Estados Unidos, é que se trata de produtos direcionados aos segmentos mais baixos da população, em que o apelo da venda direta (por meio das "consultoras") tem demonstrado efeitos bastante significativos $^{6}$.

Além disso, algumas empresas aproveitam-se das economias de escala e de escopo na comercialização para vender outros produtos em seus catálogos, como jóias, vestuário (em geral roupas íntimas) e utensílios domésticos. Por exemplo, no caso da Avon, cerca de 1/3 de seu faturamento global provém de produtos "não-cosméticos". Outro caso é o da Nu Skin, que possui uma divisão de produtos nutricionais - a Pharmanex -, que também comercializa seus produtos por meio do sistema de vendas diretas e responde por $43 \%$ do faturamento da empresa.

Em suma, a despeito das importantes diferenças que são verificadas entre as estratégias típicas das empresas internacionais da indústria de cosméticos, algumas características gerais podem ser assinaladas. Essas características são importantes, pois podem auxiliar na compreensão da dinâmica competitiva da indústria brasileira, seus principais atores e sua forma e potencialidades de inserção no mercado internacional.

\section{FATORES DE COMPETITIVIDADE NA INDÚSTRIA DE COSMÉTICOS E OS CONDICIONANTES PARA A INTERNACIONALIZAC̣ÃO DAS EMPRESAS BRASILEIRAS}

A análise das experiências e das estratégias de internacionalização na indústria de cosméticos mostra que existe um padrão no processo de expansão internacional das grandes empresas globais. A compreensão desse padrão, no entanto, não pode prescindir da investigação dos principais fatores de competitividade do setor, pois eles são os principais determinantes das formas de inserção internacional das empresas.

Deve-se ressaltar que o processo de internacionaliza- ção é um dos principais desafios que estão colocados para as empresas brasileiras de cosméticos, inclusive porque algumas delas já têm realizado alguns esforços nessa direção, inserindo a internacionalização como parte de suas estratégias competitivas. A investigação das experiências das empresas internacionais e a hierarquização dos fatores de competitividade na indústria de cosméticos são capazes de exercer papel importante na definição das estratégias das empresas brasileiras, já que algumas delas vêm dando passos importantes na busca de expansão de suas vendas na direção do mercado internacional. o caso de produtos mais sofisticados e
de menor volume de consumo interno, as empresas optam normalmente por abastecer o mercado por meio de importações

As experiências internacionais mostram, em primeiro lugar, a importância dos ativos comerciais. Normalmente, as empresas adotam estratégias vultosas de fortalecimento de seus ativos comerciais, tanto a(s) sua(s) marca(s), quanto os canais de comercialização e distribuição do produto. No seu processo de expansão internacional, as empresas procuram inicialmente fixar sua marca e construir canais de comercialização e distribuição, antes mesmo de estabelecer unidades produtoras nos mercados em que estavam ingressando. Esses esforços independem absolutamente da forma de comercialização utilizada pela empresa, que varia desde os canais tradicionais de varejo até a venda direta. E os ativos comerciais ainda possuem um caráter claramente intangível e não estão relacionados com a existência de unidades produtoras de mercadorias ${ }^{7}$.

Essa é, por sinal, a principal barreira ao desenvolvimento das pequenas e médias empresas do setor. As firmas menores, muitas vezes, podem até deter conhecimentos e capacitações técnicas de manipulação de fórmulas que lhes permitam estabelecer unidades produtivas de elevado padrão em termos de qualidade e produtividade. Porém, a ausência de canais de comercialização do produto e de marcas próprias é um fator impeditivo fundamental para o desenvolvimento do negócio, já que tais empresas são incapazes de realizar sua produção. Uma saída que tem sido crescentemente utilizada é a utilização das instalações produtivas para a fabricação de produtos sob encomenda das empresas maiores, o que permite a ocupação da capacidade produtiva e a 
complementação da linha de produtos, além de promover ganhos derivados de economias de especialização.

A ausência de ativos comerciais representa nesse sentido uma restrição ao processo de expansão internacional das empresas. As experiências internacionais mostram que a internacionalização produtiva somente ocorreu após o momento em que a empresa conseguiu fixar seus ativos comerciais nos mercados-destino, tanto por meio da marca como através do estabelecimento de canais de comercialização e distribuição do produto. Aliás, algumas empresas brasileiras, especialmente os casos citados da Natura e do Boticário, vêm enfrentando dificuldades significativas em seus processos de internacionalização justamente por não deterem ainda ativos comerciais expressivos nos mercados externos em que elas têm procurado ingressar.

No caso das empresas internacionais, a expansão dos ativos comerciais, especialmente dos canais de comercialização muitas vezes se dá por meio de contratos de parceria que são estabelecidos com empresas locais. Não raro são os casos em que as empresas adquirem, por meio de processos de fusão e aquisição, firmas locais no intuito de utilizar a marca e os canais de comercialização já constituídos.

Após a fixação de ativos comerciais no mercadodestino, as empresas optam normalmente pelo estabelecimento de unidades produtoras. A produção configura-se como um fator importante de competitividade porque os processos de manufatura de produtos cosméticos envolvem um conjunto de capacitações e competências que são específicas à firma e sustentam sua competitividade. Além disso, no processo de internacionalização da empresa, o estabelecimento de unidades locais permite que a empresa adapte seus produtos internacionais ou globais às especificidades do mercado doméstico, incrementando sua competitividade. No caso da indústria de cosméticos, esse elemento é bastante importante, já que permite às empresas adaptar seus produtos a fatores como o clima local e o tipo de pele da população.

Porém, a experiência da indústria de cosméticos no Brasil revela que a expansão dos ativos produtivos da firma por meio do investimento direto externo somente se realiza quando o estabelecimento dessas unidades é capaz de suprir a demanda local ou regional em níveis de escala economicamente viáveis. Em caso contrário, as empresas preferem abastecer o mercado local por meio do comércio externo - especialmente no caso em que a demanda doméstica não comporta volumes mais expressivos de produção.

No caso da indústria brasileira de cosméticos, nota-se que o investimento das grandes empresas internacionais segue essa lógica, já que as firmas abastecem o mercado local, e regional, com produção local nos mercados de maior escala e importam os produtos de menor volume de vendas. Essa tendência pode ser claramente verificada no mercado de produtos de higiene pessoal, em que o elevado volume consumido no Brasil foi capaz de atrair unidades produtoras de diversas empresas internacionais, como Unilever, Procter \& Gamble, Johnson \& Johnson, entre outras. Normalmente, essas unidades atendem não apenas o mercado doméstico, mas também os países vizinhos.

Já no caso de produtos mais sofisticados e menor volume de consumo interno, as empresas optam normalmente por abastecer o mercado por meio de importações, como revela o elevado volume de compras externas, especialmente oriundas dos países desenvolvidos (Tabela 7). O padrão de comércio, aliás, revela a importância da origem do capital das empresas. A concentração das unidades produtivas nos países de origem mostra que a existência de empresas de capital nacional tem efeitos muito significativos sobre a capacidade de geração de emprego e renda nesse setor.

Um dos fatores que justificam essas estratégias pode ser encontrado no segmento de perfumes da indústria de cosméticos. Alguns produtos, principalmente os de consumo mais sofisticados, que normalmente são aqueles de maior valor agregado, possuem escalas mundiais de produção, o que leva as empresas a concentrar a produção em uma determinada planta, normalmente estabelecida no país de origem.

De todo modo, foi verificado que, no geral, as empresas têm procurado formas de redução de seus custos de produção, com efeitos importantes sobre o processo de internacionalização. Uma das formas de redução dos custos encontradas pelas empresas tem sido a subcontratação de processos produtivos a empresas especializadas, em um processo semelhante ao verificado em outros setores industriais, como na indústria eletrônica e na indústria do vestuário. Muitas empresas têm adotado essa estratégia como forma de internacionalização, em que a atuação nos mercados-destino está associada à subcontratação da produção a um produtor local. Isso permite à empresa reduzir os investimentos necessários para atuar nos mercados-destino, o que pode acelerar o processo de internacionalização da firma. Muitas vezes, isso configura uma primeira etapa no processo de internacionalização da firma que, em um segundo momento, acaba realizando investimentos no estabelecimento de plantas produtivas no mercado-destino ${ }^{8}$.

Exemplo de estratégia como essa é o da empresa estadunidense Mary Kay, que tem buscado desverticalizar sua produção através da subcontratação de algumas 
linhas de produtos a empresas manufatureiras especializadas (GLOBAL COSMETIC INDUSTRY, 2000). Outro exemplo é o da empresa Clairol, braço mundial da Procter \& Gamble na indústria de cosméticos, que atua no mercado brasileiro por meio de importações, que respondem por dois terços do faturamento, e por meio de unidades produtivas subcontratadas, que são responsáveis pela terça parte restante das vendas (VALOR, 29/5/ 01). Outra empresa, a alemã Nívea, também atua no mercado brasileiro por meio da subcontratação de boa parte de sua produção (VALOR, 16/4/03).

Por fim, a última fase do processo de internacionalização das empresas de cosméticos envolve os esforços de desenvolvimento de novos produtos, especialmente de novas essências e substâncias que são incorporadas aos produtos cosméticos. Uma das características do padrão competitivo da indústria de cosméticos são os vultosos esforços de $\mathrm{P} \& \mathrm{D}$ que sustentam estratégias agressivas de novos lançamentos de produto. Porém, essa função corporativa permanece fortemente concentrada nos países de origem e em outros países desenvolvidos, onde as empresas desenvolvem seus "centros de excelência", muitas vezes aproveitando-se de contatos com universidades e centros locais de pesquisa.

Nesses esforços de desenvolvimento, as empresas mantêm relações estreitas com seus fornecedores de produtos químicos, especialmente no que se refere ao desenvolvimento de produtos e aplicações que são incorporadas aos cosméticos. Essa capacidade de desenvolvimento de tecnologias e de novas aplicações também é peça fundamental no processo de concorrência do setor de cosméticos, já que os desenvolvimentos tecnológicos são rapidamente difundidos por meio tanto das estratégias imitadoras, como pelos fornecedores de essências e fragrâncias.

Um exemplo claro da importância desses esforços de desenvolvimento de produto pode ser verificado no caso já citado da empresa francesa L'Oreal. Essa empresa possui três grandes laboratórios de desenvolvimento de produto nas áreas de cosméticos e de dermatologia, localizados na França, nos Estados Unidos e no Japão, que empregam mais de 2.900 pesquisadores (muitos deles com título acadêmico superior, mestrado e doutorado), onde investe cerca de $3 \%$ de seu faturamento mundial total, o que representa um orçamento anual de cerca de US\$ 400 milhões. No conjunto, esses laboratórios geram em média 3.000 novas formulações anualmente e, somente em 2003, resultaram em 515 novas patentes ${ }^{9}$.

Esses esforços vultosos de desenvolvimento exercem papel fundamental para sustentar a posição competitiva das empresas líderes. As empresas que são incapazes de realizar investimentos nesses montantes ficam subordinadas aos lançamentos das líderes e são obrigadas a incorporar rapidamente tais desenvolvimentos às suas respectivas linhas de produtos ${ }^{10}$.

No que se refere à internacionalização das funções de desenvolvimento de produto, as experiências internacionais mostram que raramente as empresas adotam estratégias de desconcentração dos esforços de desenvolvimento de produto. As empresas tendem a concentrar suas atividades inovativas nos países de origem, onde se localizam seus principais laboratórios de P\&D. Porém, no período recente, foi notada uma estratégia de desconcentração dessas atividades, muito embora esse processo seja ainda incipiente e esteja restrito aos países desenvolvidos. O caso da empresa francesa L'Oreal, supracitado, mostra exatamente esse fenômeno.

No caso da indústria brasileira de cosméticos, nota-se que as grandes empresas internacionais não possuem laboratórios importantes de desenvolvimento de produtos no Brasil - mesmo no caso de empresas que possuem elevadas participações no mercado doméstico. Normalmente, as empresas possuem pequenos laboratórios voltados apenas para a adaptação de seus produtos ao mercado brasileiro, na ausência de esforços mais expressivos de desenvolvimento de novos produtos, essências e muito menos princípios ativos. Os principais esforços de desenvolvimento de produto na indústria brasileira de cosméticos são verificados nas empresas nacionais, especialmente nas de maior porte.

Portanto, essas características básicas das estratégias de internacionalização das grandes empresas internacionais mostram algumas tendências que se verificam na atuação global desses atores. A tentativa de reforço dos ativos comerciais, a aproximação em direção dos fatores geradores de atributos diferenciados e a tendência de maior externalização das atividades produtivas são elementos que indicam os rumos que devem ser tomados pelas empresas nos próximos anos.

\section{CONSIDERACÕES FINAIS E IMPLICACÕES PARA AS EMPRESAS BRASILEIRAS}

O padrão competitivo e de comércio internacional da indústria de cosméticos mostra alguns elementos importantes que caracterizam a estratégia das grandes empresas internacionais. A elevada participação dos países desenvolvidos no mercado mundial e as formas de internacionalização das empresas indicam a importância da atuação global das firmas nas áreas produtiva e sobretudo comercial. Essa análise pode ter implicações importantes para as empresas brasileiras, que atendem parcelas significativas do mercado doméstico, mas apresentam 
participações muito modestas no mercado internacional, mesmo que tenham procurado no período recente estabelecer estratégias de internacionalização.

Tomando inicialmente as empresas que atuam em segmentos mais nobres do mercado. A partir de bases produtivas localizadas nos países desenvolvidos, e especialmente nos países de origem, as empresas abastecem o mercado mundial através do comércio internacional. O caso da França é paradigmático nesse sentido, dada a elevada participação desse país no mercado internacional, que decorre do vigor competitivo de sua indústria. lado, verifica-se a presença de algumas empresas brasileiras que possuem participações expressivas no mercado doméstico, decorrente principalmente da posse de importantes capacitações industriais e sobretudo comerciais.

Essas lições têm papel importante para as estratégias de internacionalização de empresas brasileiras de cosméticos, que já têm dado alguns passos, ainda que tímidos, na direção da expansão das operações externas. Nesse sentido, uma condição necessária para a internacionalização é o domínio de ativos comerciais nos mercados-destino onde as empresas pretendem atuar. O exemplo do Boticário em Portugal mostra isso claramente, já que o sucesso de sua estratégia nesse país deve-se fundamentalmente ao esforço de estabelecimento e estruturação do sistema de franquias no Brasil. O mesmo fenômeno se verifica nos investimentos da Natura nos diversos países em que ela tem procurado atuar.

Assim, as empresas brasileiras devem concentrar seus esforços de inter-

Outro caso é o das empresas que atuam em segmentos mais populares do mercado e, por isso, mais intensivos em escala de produção e comercialização. Nesses casos, as empresas tendem a internacionalizar mais a função produtiva, através do estabelecimento de unidades produtoras nos países hospedeiros, que abastecem o mercado local e, eventualmente, regional.

Vale ressaltar ainda que as empresas tendem a concentrar seus esforços de $\mathrm{P} \& \mathrm{D}$ nos países centrais, onde estão localizados os seus principais laboratórios de desenvolvimento de produtos. Os "laboratórios locais" são utilizados, quando muito, apenas para a adaptação desses produtos ao mercado em que vão atuar, especialmente quando se trata de produtos cosméticos, em que a importância de fatores climáticos é mais significativa.

Isso é claramente verificado no caso da indústria brasileira de cosméticos, já que as empresas internacionais que atuam no Brasil não dedicam esforços expressivos de desenvolvimento de produto. Nesse sentido, verifica-se que as grandes empresas internacionais adotam estratégias tipo market seeking, já que sua atuação está fortemente restrita à exploração do mercado doméstico e, em alguns casos, do Mercosul. Por outro nacionalização inicialmente na área comercial. Uma possível estratégia é o estabelecimento de parcerias com agentes locais, que se ocupariam da distribuição dos produtos em cada um dos mercados-destino. As empresas não devem descartar ainda a possibilidade de fusões e aquisições de companhias locais, estratégia que pode representar um caminho mais curto na internacionalização dessas empresas.

Um último ponto a ser destacado relaciona-se com o pequeno tamanho econômico das empresas brasileiras de cosméticos, especialmente quando comparado com o das grandes firmas internacionais. À exceção dos dois casos mais bem-sucedidos, da Natura e do Boticário, as firmas brasileiras são muito pequenas, o que certamente dificulta o acesso aos recursos necessários para financiar o processo de expansão internacional ${ }^{11}$. Além disso, ao contrário da maior parte das empresas, as firmas brasileiras são monomarca, o que acaba por representar um estreitamento da faixa de atuação no mercado.

As questões levantadas representam desafios que estão colocados para um eventual processo de internacionalização das empresas brasileiras de cosméticos, que já possuem participação expressiva no mercado doméstico de diversos produtos na indústria de cosméticos. 


\section{- Notas}

*Este trabalho está inserido em um esforço coletivo de pesquisa que envolve estudiosos do GEEIN - Grupo de Estudos em Economia Industrial e do Departamento de Engenharia de Produção da Escola Politécnica da USP. O autor agradece particularmente João Furtado, Susana Salomão e Andresa Francischini pelo apoio e pelas discussões que auxiliaram na elaboração e no aperfeiçoamento deste trabalho. Como de praxe, as insuficiências são de responsabilidade exclusiva do autor.

1. O mais notório desses casos no Brasil é o da empresa O Boticário, que teve sua origem em uma pequena farmácia de manipulação na cidade de Curitiba.

2. Uma breve resenha dessas abordagens e interpretações está apresentada em Gonçalves (2002).
3. Uma dificuldade importante da análise da indústria de cosméticos, que está presente em todo o trabalho, é a sua delimitação, já que muitas vezes ela se insere no âmbito de segmentos como perfumaria, higiene pessoal e limpeza, além de suas ligações, mesmo que mais distantes, com a indústria química e a de alimentos.

4. Esse aspecto é tratado por Dweck (1998). Para a autora, o crescimento nas últimas décadas do que ela chama de indústria da beleza (que envolve produtos como perfumaria e cosméticos e servicos como salões de beleza, clínicas de estética e academias de esportes) está associado à sofisticação dos hábitos de consumo da população.

5. Informações coletadas na ABEVD - Associação Brasileira de Empresas de Vendas Diretas.
6. Vale a observação de que no Brasil, ao contrário do que ocorre nos Estados Unidos, as vendas diretas não estão associadas necessariamente com o consumo de produtos populares.

7. Um elemento que denota a importância desses ativos comerciais intangíveis é a embalagem do produto, peça fundamental nas estratégias de diferenciação das empresas. Diversos profissionais do setor declararam que as embalagens chegam a representar até $70 \%$ do custo final dos produtos. Além do mais, uma das diferenças entre os produtos básicos e os mais sofisticados é justamente a embalagem.

8. Como as empresas utilizam-se dessa estratégia como forma de acumular conhecimentos sobre a demanda local, em alguns casos, elas acabam abandonando suas estratégias de expansão nesse mercado.
9. Apenas para fins de comparação, vale apontar que a Natura, empresa que realiza o maior investimento em P\&D no Brasil, realizou em 2003 un orçamento de RS 18 milhões. Trata-se de um valor expressivo quando comparado com o padrão brasileiro, mas muito pequeno na comparação com as grandes empresas internacionais.

10. De acordo com profissionais ligados ao setor, as pequenas empresas incorporam esses desenvolvimentos para as suas linhas de basicamente duas formas: pela simples imitação dos produtos lançados ou por meio dos fornecedores de essências. Além disso, quando do lançamento de novos produtos, raramente as grandes empresas conseguem atender toda a demanda, o que abre espaços para os concorrentes de pequeno e médio porte.

11. Mesmo quando comparado com o das grandes empresas brasileiras, a diferença ainda permanece flagrante. Por exemplo, a maior empresa brasileira do setor, a Natura, apresentou um faturamento em 2003 de RS 1,9 milhão, contra os $\in 14$ bilhões da L'Oreal no mesmo ano.

\section{- Referências Bibliográficas}

ANDERSEN, O. (1993). On the internationalization process of firms: a critical analysis. Journal of International Business Studies, v. 24, n. 2, p. 209-231.

CHESNAIS, F. A mundialização do capital. São Paulo: Xamã, 1996.

DWECK, R.H. A beleza como variável econômica: reflexo nos mercados de trabalho e de bens e serviços. Texto para discussão IPEA n. ${ }^{\circ}$ 618, 1999.
DUNNING, J. The globalization of business. London: Routledge, 1993.

FURTADO, J.; VALLE, M.R. Globalização, estabilização e colapso da empresa nacional. In: Economia e Sociedade, n. 16, jun, 2001.

GARCIA, R.; FURTADO, J.; HIRATUKA, C.; SABATTINI, R; MATUSITA, A.P. Indústria de cosméticos: elementos para uma caracterização de sua estrutura e dinâmica com base num enfoque de cadeia produtiva. Campinas: IE/ UNICAMP, 2000
GARCIA, R.; FURTADO, J. A indústria de cosméticos - estudo de competitividade por cadeias integradas. São Paulo: EPUSP. Disponível em h t t p ://www.m di c.gov.br/ cadeiasprodutivas/doc/ 31 cosmeticosCompleto.PDF, 2002.

GONÇALVES, R. "A empresa transnacional". In: KUPFER, D.; HASENCLEVER, L. Economia Industrial: fundamentos teóricos e práticos no Brasil. Rio de Janeiro: Campus, 2002.
STURGEON, T. Modular production network: a new American model of industrial organization. Indus trial and Corporate Change, n. 11 v. 3, 2002.

VIEIRA, S.P. O processo de internacionalização da indústria brasileira de cosméticos. Campinas: IE/ UNICAMP (Relatório de iniciação científica apresentado à FAPESP), 2002.

\section{- Sobre o autor}

\section{Renato Garcia}

Escola Politécnica da USP (EPUSP), Depto. Eng. de Produção.

Endereço: Av. Prof. Almeida Prado, travessa 2, $\mathrm{n}^{\circ} 128$

CEP: 05.508-900 São Paulo - SP - Brasil

Fone: (11) 3091 5363, r. 437

Fax: (11) 30915399

Endereço eletrônico: renato.garcia@poli.usp.br 